\title{
Dispositional and induced optimism lead to attentional preference for faces displaying positive emotions: An eye-tracker study
}

Citation for published version (APA):

Peters, M. L., Vieler, J. S. E., \& Lautenbacher, S. (2016). Dispositional and induced optimism lead to attentional preference for faces displaying positive emotions: An eye-tracker study. Journal of positive psychology, 11(3), 258-269. https://doi.org/10.1080/17439760.2015.1048816

Document status and date:

Published: 03/05/2016

DOI:

10.1080/17439760.2015.1048816

Document Version:

Publisher's PDF, also known as Version of record

\section{Document license:}

Taverne

Please check the document version of this publication:

- A submitted manuscript is the version of the article upon submission and before peer-review. There can be important differences between the submitted version and the official published version of record.

People interested in the research are advised to contact the author for the final version of the publication, or visit the DOI to the publisher's website.

- The final author version and the galley proof are versions of the publication after peer review.

- The final published version features the final layout of the paper including the volume, issue and page numbers.

Link to publication

\footnotetext{
General rights rights.

- You may freely distribute the URL identifying the publication in the public portal. please follow below link for the End User Agreement:

www.umlib.nl/taverne-license

Take down policy

If you believe that this document breaches copyright please contact us at:

repository@maastrichtuniversity.nl

providing details and we will investigate your claim.
}

Copyright and moral rights for the publications made accessible in the public portal are retained by the authors and/or other copyright owners and it is a condition of accessing publications that users recognise and abide by the legal requirements associated with these

- Users may download and print one copy of any publication from the public portal for the purpose of private study or research.

- You may not further distribute the material or use it for any profit-making activity or commercial gain

If the publication is distributed under the terms of Article $25 \mathrm{fa}$ of the Dutch Copyright Act, indicated by the "Taverne" license above, 


\section{Dispositional and induced optimism lead to attentional preference for faces displaying positive emotions: An eye-tracker study}

\section{Madelon L. Peters, Julia S.E. Vieler \& Stefan Lautenbacher}

To cite this article: Madelon L. Peters, Julia S.E. Vieler \& Stefan Lautenbacher (2016) Dispositional and induced optimism lead to attentional preference for faces displaying positive emotions: An eye-tracker study, The Journal of Positive Psychology, 11:3, 258-269, DOI: 10.1080/17439760.2015.1048816

To link to this article: https://doi.org/10.1080/17439760.2015.1048816

Published online: 01 Jun 2015.

Submit your article to this journal $\sqsubset$

Џll Article views: 1014

Q View related articles $\sqsubset$

View Crossmark data $־$

Citing articles: 16 View citing articles 


\title{
Dispositional and induced optimism lead to attentional preference for faces displaying positive emotions: An eye-tracker study
}

\author{
Madelon L. Peters ${ }^{\mathrm{a} *}$, Julia S.E. Vieler ${ }^{\mathrm{b}}$ and Stefan Lautenbacher ${ }^{\mathrm{b}}$ \\ ${ }^{a}$ Department of Clinical Psychological Science, Maastricht University, Maastricht, The Netherlands; ${ }^{b}$ Department Physiological \\ Psychology, University of Bamberg, Bamberg, Germany
}

(Received 8 September 2014; accepted 8 April 2015)

\begin{abstract}
The aim of this study was to examine whether dispositional optimism and induced optimism are associated with an attentional bias for positive stimuli. Fifty-six healthy participants performed an eye-tracking task twice, while their gazing time at faces displaying joy, anger, pain, or a neutral expression was measured. Participants scoring high on dispositional optimism tended to gaze longer at joy faces during the first face-presentation trial compared to participants scoring lower on optimism, and this correlation became significant during the second face-presentation trial. In between the two presentations, participants received either an optimism manipulation or a control manipulation. There was no effect of type of manipulation on gazing behavior but post hoc analyses demonstrated that participants showing an increase in state optimism displayed a significant decrease in gaze duration for anger faces and a nearly significant increase in gaze duration for joy faces.
\end{abstract}

Keywords: optimism; Best Possible Self manipulation; attentional bias; eye tracking; emotional faces

People tend to overestimate their chances to obtain good outcomes and underestimate their chances to experience negative outcomes in life, a phenomenon known as optimistic bias (Weinstein, 1980). People base their predictions of the future on mental simulation of themselves in this future, and because the future is per definition uncertain, mental scenarios may become idealized (Armor \& Taylor, 1998). Although there is thus a general tendency to make positive predictions for the future, people scoring high on dispositional optimism may be even stronger inclined to underestimate negative and overestimate positive future events. When confronted with vignettes of ambiguous situations, dispositional optimistic people more often choose for a less negative or even positive interpretation of the situation compared to people with a more pessimistic attitude (Hanssen, Vancleef \& Peters, in press; Vancleef \& Peters, 2008). Converging lines of evidence suggest that one of the underlying mechanisms of these rose-colored expectancies may be due to the fact that optimists have a superior capacity to generate future positive scenarios. A brain imaging study found that during positive imagery of the future optimists display higher activity in brain regions involved in assessing the salience of emotional and motivational information (Sharot, Korn, \& Dolan, 2011) and a recent survey study showed that the vividness with which a person could generate positive mental images of the future was significantly associated with his or her level of optimism (Blackwell et al., 2013).
Optimism may already affect the early, still implicit and preconscious stages of information processing: selection and encoding of information (Carver, 2001; Isaacowitz, 2005; Karademas, Kafetsios, \& Sideridis, 2007; Tamir \& Robinson, 2007). Indeed, there may be a fundamental difference in the way optimists and pessimists look at the world, with optimists focusing more on positive stimuli and events and pessimists more of negative ones as a general also implicitly working mind set. A few studies have directly studied attentional patterns as a function of an individual's level of optimism. Segerstrom (2001) found that in an emotional stroop task, higher levels of optimism were related to an increased attentional bias toward positive words and a decreased bias toward negative words, an effect that was maintained after controlling for current mood states. Similarly, Karademas et al. (2007) found dispositional optimism to be associated with more attention toward well-being words in an emotional stroop task. Finally, an eye-tracking study demonstrated that participants scoring high on optimism were less likely to rest their gaze on negative pictures (cancer images) than those scoring low on optimism (Isaacowitz, 2005), also after controlling for mood. Positive pictures were not included in this study.

Optimism and attention for positive stimuli may have a bidirectional relationship. People with high levels of optimism preferentially select positive stimuli in the environment because these are congruent with their positive schemas; in turn, attention to positive stimuli

\footnotetext{
*Corresponding author. Email: Madelon.peters@maastrichtuniversity.nl 
maintains these positive schemas (Wadlinger \& Isaacowitz, 2006). Accordingly, positive interventions teaching people to redirect their focus toward positive environmental stimuli may lead to an upward spiral of increased positive affect and increased levels of optimism (Garland et al., 2010). That an induced positive orientation can have implications for subsequent information processing strategies is demonstrated by studies using positive imagery training. Training people to focus on positive outcomes and to interpret ambiguity in a positive fashion leads to more benign interpretations of ambiguous homophones and more positive resolutions of scrambled sentences (Holmes, Lang, \& Shah, 2009; Pictet, Coughtrey, Mathews, \& Holmes, 2011; Torkan et al., 2014). In addition, positive interpretation training can induce a positive memory bias (Tran, Hertel, \& Joormann, 2011). However, so far, the effects of positive interventions on attention deployment when positive and negative stimuli compete for cognitive resources have not been examined.

This study therefore sought to examine whether making people imagine positive future scenarios would lead them to selectively engage with positive stimuli and to disengage from negative stimuli. For that purpose, participants performed the Best Possible Self (BPS) manipulation, a writing and visualization exercise in which they imagined a life in the future where everything has gone well. Previously, this manipulation was found to temporary increase optimism and positive affect (Peters, Flink, Boersma, \& Linton, 2010; Renner, Schwarz, Peters, \& Huibers, 2014). Eye tracking was used to assess gazing time toward positive (joy) and negative (anger) faces which were presented in separate trials relative to a neutral face. In addition, pain faces were included for exploratory purposes. Previously, we found that the BPS manipulation led to decreased pain sensitivity and less interference of performance by pain (Boselie, Vancleef, Smeets, \& Peters, 2014; Hanssen, Peters, Vlaeyen, Meevissen, \& Vancleef, 2013), and we speculated that this might be due to less attention toward pain.

Gaze direction was measured at two separate occasions within a single experimental session. After the initial assessment, half of the participants underwent the BPS manipulation to induce state optimism, whereas the other half underwent a control manipulation where they wrote about a neutral topic. A passive viewing paradigm was used, i.e. without a task-relevant behavioral goal. This meant that participants could freely look around and use the pictures to fuel their optimism. The following hypotheses were formulated as: (1) Dispositional optimism is related to baseline gazing behavior, with optimistic individuals looking more at positive and less at negative faces; (2) the BPS manipulation increases optimism and thereby leads to an increase in gazing at positive faces and a decrease in gazing at negative faces; and (3) especially participants scoring low on dispositional optimism show increased gazing at positive faces and decreased gazing at negative faces following the BPS manipulation.

\section{Materials and methods}

\section{Subjects}

Fifty-six students (32 female) with a mean age of 23.5 years $(\mathrm{SD}=3.3)$ participated for course credits or payment. Only participants without psychiatric, neurological, or somatic disorders were accepted for the study. None of the participants suffered from acute or chronic pain. All subjects had normal or corrected-to-normal vision (self-report). The study protocol was approved by the ethics committee of the Otto-Friedrich University of Bamberg.

\section{Apparatus and stimulus material}

\section{Eye tracking}

Pictures of male and female human faces were extracted from the 'Montréal Pain and Affective Face Clips' (Simon, Craig, Gosselin, Belin, \& Rainville, 2008). We used pictures of facial expressions displaying joy (positive emotional), anger (negative emotional), pain (pain-related) and pictures of neutral face expressions. In order to minimize emotional effects caused by color, colored extracted pictures were transformed into monochrome pictures. The suitability and validity of this set of pictures was confirmed in two studies in our lab, one recognition study (Baum, Kappesser, Schneider, \& Lautenbacher, 2013) and one dot-probe study (Baum, Schneider, Keogh, \& Lautenbacher, 2013).

For this study, 64 pairs of pictures were produced. Forty-eight of those pairs consisted of one picture depicting a neutral facial expression and one picture depicting an emotional or painful expression (i.e. 16 neutral-joy, 16 neutral-anger and 16 neutral-pain pairs). The screen position (left-right) of the neutral picture was randomized in order to eliminate position effects. As control condition, 16 pairs consisting of two neutral faces were included. We used only 16 neutral faces to pair the emotional and painful face expressions with exactly the same neutral stimuli. Accordingly, the neutral stimuli were used repeatedly. Due to the random order of the pair of pictures, the increasing familiarity of the subjects with the neutral faces affected the three emotional categories (anger, joy, pain) in a similar fashion.

All pictures were $7.8 \mathrm{~cm}$ wide and $6.1 \mathrm{~cm}$ high, and the two pictures were horizontally aligned. The distance between the two pictures forming a pair was $4.8 \mathrm{~cm}$. Stimuli were presented vertically centered against a 
black background on a 19-in. monitor with a resolution of $1280 \times 1024$ pixels. Stimulus presentation and registration of ocular movements were accomplished by an Interactive-Mind system being composed of a desktop-PC with Intel-Processor, 19-in. LED-screen and the monocular eye-tracking system Eyegaze EdgeTM (LC Technologies, Inc., VA, USA). In order to measure the eye's orientation, this system used the corneal reflection of an infrared light source (corneal reflex method). Eye movements were recorded with a sampling rate of $60 \mathrm{~Hz}$ and an accuracy of $.4^{\circ}$. Gaze direction was accepted as fixation if participants' gaze did not deviate more than $.7^{\circ}$ from the center of the actual fixation for at least $100 \mathrm{~ms}$. For stimulus presentation and registration of ocular movements, the system was controlled by the software NYAN 2XT (version 2.3.3). An advantage of this system is that participants do not have to wear helmets or contacts which might limit their (gazing) behavior. A kind of a camera, which was placed below the screen, recorded the position of one eye.

\section{Questionnaires}

\section{Trait questionnaires}

The Life Orientation Test-Revised (LOT-R; Scheier, Carver, \& Bridges, 1994) was used to assess the level of dispositional optimism. The LOT-R has 10 items that are rated on a 5-point Likert scale, ranging from 0 ('strongly disagree') to 4 ('strongly agree'). There are 3 positively phrased items, 3 negatively phrased items, and 4 filler items. A total sore was calculated after reversing the negatively phrased items.

The Fear of Pain Questionnaire (FPQ-III; McNeil \& Rainwater, 1998) was used to measure participants' painrelated fear. The FPQ-III was developed as a comprehensive measure of fear of pain and validated in a pain-free population as well as in chronic back pain patients. Participants are instructed to rate the degree of fear they would likely experience if confronted with a variety of potentially painful situations, like 'breaking an arm', 'receiving an injection in the mouth' or 'paper cut on the finger'. The FPQ-III contains 30 items which are rated on a 5-point scale, ranging from 1 ('not at all') to 5 ('very strong').

The Pain Vigilance and Awareness Questionnaire (PVAQ) was developed as a comprehensive measure of attention to pain and has been validated for the use in chronic pain and non-clinical samples (McCracken, 1997). It consists of 16 items that are rated on a six-point scale and assesses awareness, vigilance, preoccupation, and observation of pain $(0=$ 'never' and $5=$ 'always'). A sum score across all items was calculated.

\section{State questionnaires}

The Future Expectancies Scale (FEX; Hanssen et al., in press) was administered to assess state optimism. The FEX consists of 10 statements describing a positive future event and 10 statements describing a negative future event. Participants rated the likelihood that they will experience each specific events on a 7-point Likert scale, ranging from 1 ('not at all likely to occur') to 7 ('extremely likely to occur'). The FEX has previously been demonstrated to be responsive to an optimism manipulation (Boselie et al., 2014; Hanssen et al., in press). The sub-scores FEX positive and FEX negative were used for further analyses.

Mood was assessed with the Positive and Negative Affect Schedule (PANAS; Watson, Clark, \& Tellegen, 1988). The PANAS consists of 20 items measuring positive (10 items) and negative (10 items) affect. Participants indicate the degree to which a certain feeling is present at that moment on a 5-point Likert scale ranging from 1 ('not at all') to 5 ('extremely'). The sub-scores PANAS positive (PA) and PANAS negative (NA) were used for further analyses.

For the PANAS and the LOT-R, validated German versions were available (Glaesmer, Hoyer, Klotsche, \& Herzberg, 2008; Krohne, Egloff, Kohlmann, \& Tausch, 1996). The FPQ-III, PVAQ and FEX were translated into German by the authors. This was done using a standard 'forward-backward' procedure. Only if the resulting backward English version was similar to the original version according to the evaluation of an English native speaker, translation accuracy was considered sufficient. The FPQIII and the PVAQ have already been used in several studies of the authors with good results (e.g. Baum, Kappesser, et al., 2013; Baum, Schneider, et al., 2013).

\section{Procedure}

After giving informed consent, participants filled out the trait questionnaires (LOT-R, FPQ-III, PVAQ) while sitting at a small table. Thereafter, the participants were seated $70 \mathrm{~cm}$ in front of the screen of the computer controlling the eye tracker, with their chin positioned on a height-adjustable chin rest. An orthogonal prolongation of the nasion had to target the center of the screen. Next, the participants ran through an automatic calibration procedure for relating eye gaze and screen positions. After that, the first eye-tracking assessment was started.

At the beginning of each trial, a fixation cross was presented in the center of the screen for $500 \mathrm{~ms}$. Participants were instructed to fixate their eyes on the cross. After the fixation cross had disappeared, one of the 64 picture pairs appeared for $2000 \mathrm{~ms}$. Next, the screen turned black for $2000 \mathrm{~ms}$, before the next trial began with the fixation cross. All participants performed 
64 trials, in which the 64 picture pairs were presented in the same random order for all subjects. The whole eyetracking procedure lasted around $10 \mathrm{~min}$. Thereafter, the participants returned to the small table, to complete the measures for the first assessment of state optimism (FEX) and mood (PANAS).

Next, the induction of optimism started. Optimism was induced by the BPS manipulation, a positive future thinking technique based on work by King (2001). BPS has been proven effective in increasing positive affect and positive future expectancies (Peters et al., 2010) Participants were instructed to carry out a writing and imagery exercise. Half of the participants were assigned to the BPS condition $(n=28)$, which required them to write about a life in the future where everything had turned out for the best. The other half of the participants were assigned to the control condition $(n=28)$, which consisted of writing about a typical day (TD). The instructions for BPS and TD were as follows (cf. Sheldon \& Lyubomirsky, 2006). BPS condition:

Thinking about your best possible self means that you imagine yourself in the future, after everything has gone as well as it possibly could. You have worked hard and succeeded at accomplishing all the goals of your life. Think of this as the realization of your dreams, and that you have reached your full potential.

\section{TD condition:}

Thinking about your typical day means that you take notice of ordinary details of your day that you usually don't think of. These might include particular classes or meetings you attend to, people you meet, things you do, typical thoughts you have during the day. Think of this as moving through your typical day, hour after hour.

Both manipulations had the same procedural format: Participants were requested to think for $1 \mathrm{~min}$ about what to write, then to write uninterrupted for $15 \mathrm{~min}$, followed by $5 \mathrm{~min}$ of imagining the story they had just finished writing. Instructions were given both verbally and in writing. The manipulation check followed immediately by asking the participants to fill out the FEX and PANAS for a second time. Next, the eyetracking procedure was run for a second time in an identical manner as the first time. This was followed by a third assessment of state optimism and mood (FEX and PANAS). After roughly one hour, the participants were debriefed and the session was concluded.

\section{Primary data analysis and eye-tracking parameters}

First, areas of interest (AOI) were defined. The AOIs were squares of $7.8 \mathrm{~cm} \times 6.1 \mathrm{~cm}$ framing the pictures of the faces. Fixations of faces were classified as such and counted if the participant gazed more than $100 \mathrm{~ms}$ at the AOI of the corresponding face. Second, a fixation bias score was computed, which was defined as the total fixation time for emotional or pain faces minus fixation time for the neutral face for each pair of pictures over the $2000 \mathrm{~ms}$ of presentation.

\section{Statistical analysis}

SPSS version 22 was used for analysis. Descriptive statistics are given as mean and standard deviation (SD). For simple within- and between-subjects comparisons, $t$-tests for dependent and independent samples were used. The association between trait questionnaires and baseline gaze behavior was examined using Pearson correlations for FPQ-III and PVAQ and Spearman correlations for LOT-R because of a strong left skew. Pre- and postmanipulation scores on the FEX and PANAS were subjected to $2 \times 3$ analysis of variance (ANOVA) for repeated measurements with the between-subjects factor 'condition' (BPS vs. TD), and the within-subjects factors 'time' (pre- vs. 1st post-manipulation assessment vs. 2nd post-manipulation assessment) as manipulation check. Next, a $2 \times 2 \times 3$ ANOVA for repeated measurements was conducted with the between-subjects factor 'condition' (BPS vs. TD), and the within-subjects factors 'time' (pre- vs. post-manipulation) and 'expression' (anger vs. joy vs. pain faces) on the dependent variable 'fixation bias'. The condition $\times$ time and the condition $\times$ time $\times$ expression interaction respectively indicate whether optimism induction changes gazing behavior toward emotional and pain faces in general or toward a specific type of facial expression.

Next, whether participants scoring low on dispositional optimism changed their gazing behavior more after the BPS manipulation compared to high scoring participants was examined by adding the dichotomized LOT-R score (median split) as an additional factor to the repeated measures ANOVA. Thus, a 2 (dispositional optimism $) \times 2 \quad($ condition $) \times 2 \quad($ time $) \times 3 \quad($ expression $)$ analysis with the dependent variable 'fixation bias' was conducted. Finally, as a post hoc test, the primary $2 \times 2 \times 3$ analysis was repeated with participants sufficiently responding to the induction of optimism (for the definition of responding, see Results). For that purpose, the between-subjects factor 'condition' was substituted by the new between-subjects factor 'Responder' (yes/no).

Post hoc testing with $t$-tests for dependent or independent sample was applied in case of significance. The alpha-level was set to $p=.05$. 


\section{Results}

\section{Characteristics of subjects}

The questionnaire data are given in Table 1. Participants in this study scored somewhat higher on dispositional optimism compared to previously published age-adjusted norm scores for the German population (Glaesmer et al., 2012). The scores on FPQ-III and PVAQ were comparable to those found in earlier studies (Baum, Kappesser, et al., 2013; Baum, Schneider, et al., 2013; Hanssen et al., in press). Despite randomization, participants in the BPS condition scored significantly higher on dispositional optimism and significantly lower on fear of pain at baseline. Therefore, all ANOVAs were repeated with the covariates dispositional optimism or fear of pain in separate analyses. There were no significant differences between the two groups in any of the other baseline measures (PVAQ, PANAS, or FEX scores).

\section{Correlations between trait questionnaire scores and baseline gaze behavior}

The only significant correlation between trait characteristics and gaze behavior was between pain vigilance and fixation bias for joy faces (pearson's $r=-.270, p=.043$ ). The correlation between dispositional optimism and fixation bias for joy faces showed a trend toward significance (Spearman's $\rho=.227, p=.09$ ). However, one participant had an extremely low score on the LOT-R, which deviated more than 3 SD from the mean score, and can be considered an outlier. Moreover, this proved to be an influential data point according to both Mahalanobis and Cook's distance. Removing this participant resulted in a significant correlation of dispositional optimism with fixation bias for joy faces $(r=.287, p=.034)$.

\section{Effects of the optimism manipulation on state optimism and mood}

Table 2 shows the ratings on the positive and negative items of the Future Expectancies Scale (FEX-pos and
FEX-neg) and Positive and Negative Affect Schedule (PANAS PA and NA) for the three assessment periods in each condition. A $2 \times 3$ repeated measures ANOVA demonstrated significant condition $\times$ time effects for FEX-pos, FEX-neg, and PA (see Table 2). Entering dispositional optimism as a covariate in the analyses did not change the results. Within condition analyses of repeated measurements with planned contrasts indicated that in the BPS condition (optimism induction), FEX-pos was significantly larger at both post-manipulation assessments points compared to the pre-manipulation assessment $(1 \mathrm{st}$ post-assessment: $F(1,27)=31.2, \quad p<.001$, $\eta_{\mathrm{p}}{ }^{2}=.536 ; \quad$ 2nd post-assessment: $\quad F(1,27)=12.7$, $\left.p=.001, \eta_{\mathrm{p}}{ }^{2}=.320\right)$, and FEX-neg was significantly smaller at both post-manipulation assessment points (1st post-assessment: $\quad F(1,27=36.4), \quad p<.001, \quad \eta_{\mathrm{p}}{ }^{2}=.574$; 2nd post-assessment: $\quad F(1,27)=25.6, \quad p<.001$, $\eta_{\mathrm{p}}{ }^{2}=.486$ ). In the TD (control) condition, the FEX scores did not significantly differ from pre-manipulation at either post-manipulation time point. PA significantly increased immediately after the manipulation in both conditions (BPS: $F\left(1,27=44.1, p<.001, \eta_{\mathrm{p}}^{2}=.620\right.$; TD: post-assessment: $\quad F(1,27=7.98, \quad p=.009$, $\left.\eta_{\mathrm{p}}{ }^{2}=.228\right)$, but had returned to baseline levels at the third assessment point, i.e. after the eye-tracking task. Negative affect did not change from the pre- to post-manipulation in either condition. Thus, the manipulation affected both positive and negative expectancies and positive affect, but not negative affect, which is in accordance with earlier studies using the same manipulation (Hanssen et al., in press; Peters et al., 2010). It is also of note that the effects on expectancies outlasted the mood effect, the former still being present at the conclusion of the experiment (around $20 \mathrm{~min}$ after the end of induction).

\section{Effects of optimism condition on gaze behavior}

Figure 1 shows the fixation bias for joy, anger, and pain faces pre- and post-manipulation in the two conditions,

Table 1. Mean \pm SD of the questionnaire data for the groups 'Best Possible Self' (BPS; induction of optimism) and 'Typical Day' (TD; control condition) as well as for the responders and non-responders to the optimism induction.

\begin{tabular}{lcrr}
\hline & BPS $(n=28)$ & TD $(n=28)$ & $t$-test \\
\hline LOT-R & $19.5 \pm 2.2$ & $17.9 \pm 3.6$ & $T=2.06 ; p=.045$ \\
FPQ-III & $67.0 \pm 16.5$ & $76.3 \pm 12.7$ & $T=-2.36 ; p=.022$ \\
PVAQ & $32.9 \pm 11.1$ & $36.7 \pm 8.6$ & $T=-1.45 ; p=.153$ \\
& Responder $(n=30)$ & Non-responder $(n=26)$ & $T=.12 ; p=.907$ \\
LOT-R & $18.6 \pm 3.0$ & $18.7 \pm 3.3$ & $T=1.60 ; p=.116$ \\
FPQ-III & $68.8 \pm 18.2$ & $75.0 \pm 10.7$ & $T=-.49 ; p=.621$ \\
PVAQ & $35.4 \pm 11.5$ & $34.1 \pm 8.3$ & \\
\hline
\end{tabular}

Notes: FPQ - Fear of pain questionnaire.

PVAQ - Pain vigilance and awareness questionnaire.

LOT-R - Life orientation test-revised. 
Table 2. Mean \pm SD of the state optimism (FEX-pos and FEX-neg) and affect (PA and NA) for the groups 'Best Possible Self' (BPS; induction of optimism) and 'Typical Day' (TD; control condition) pre-intervention (pre), immediately post-intervention (1st post) and at the end of the session (2nd post).

\begin{tabular}{|c|c|c|c|c|c|c|c|}
\hline & \multicolumn{3}{|c|}{$\operatorname{BPS}(n=28)$} & \multicolumn{3}{|c|}{$\mathrm{TD}(n=28)$} & \multirow[b]{2}{*}{ Time $\times$ condition effect } \\
\hline & Pre & 1st post & 2nd post & Pre & 1st post & 2nd post & \\
\hline FEX-pos & $55.5 \pm 5.6$ & $58.8 \pm 5.9^{*}$ & $57.6 \pm 6.2^{*}$ & $52.5 \pm 6.5$ & $53.7 \pm 7.1$ & $53.9 \pm 7.2$ & $F(2,53)=3.70, p=.031, \eta_{\mathrm{p}}{ }^{2}=.123$ \\
\hline FEX-neg & $25.3 \pm 7.3$ & $21.2 \pm 7.6^{*}$ & $21.9 \pm 7.7^{*}$ & $27.0 \pm 7.2$ & $26.5 \pm 7.8$ & $25.8 \pm 7.7$ & $F(2,53)=7.15, p=.002, \eta_{\mathrm{p}}^{2}=.212$ \\
\hline PA & $28.9 \pm 5.4$ & $35.5 \pm 6.0^{*}$ & $27.9 \pm 8.0$ & $26.9 \pm 4.6$ & $30.0 \pm 7.7^{*}$ & $26.8 \pm 7.6$ & $F(2,53)=5.16, p=.009, \eta_{\mathrm{p}}{ }^{2}=.163$ \\
\hline NA & $12.4 \pm 3.4$ & $12.2 \pm 3.1$ & $12.0 \pm 3.3$ & $12.8 \pm 5.1$ & $12.4 \pm 3.5$ & $12.4 \pm 4.3$ & $F(2,53)=.11, p=.901, \eta_{\mathrm{p}}{ }^{2}=.004$ \\
\hline
\end{tabular}

Notes: FEX - Questionnaire for Future Expectation (pos - positive expectations; neg - negative expectations).

PA - positive affect; NA - negative affect.

*Score significantly different from the pre-intervention score in that condition.

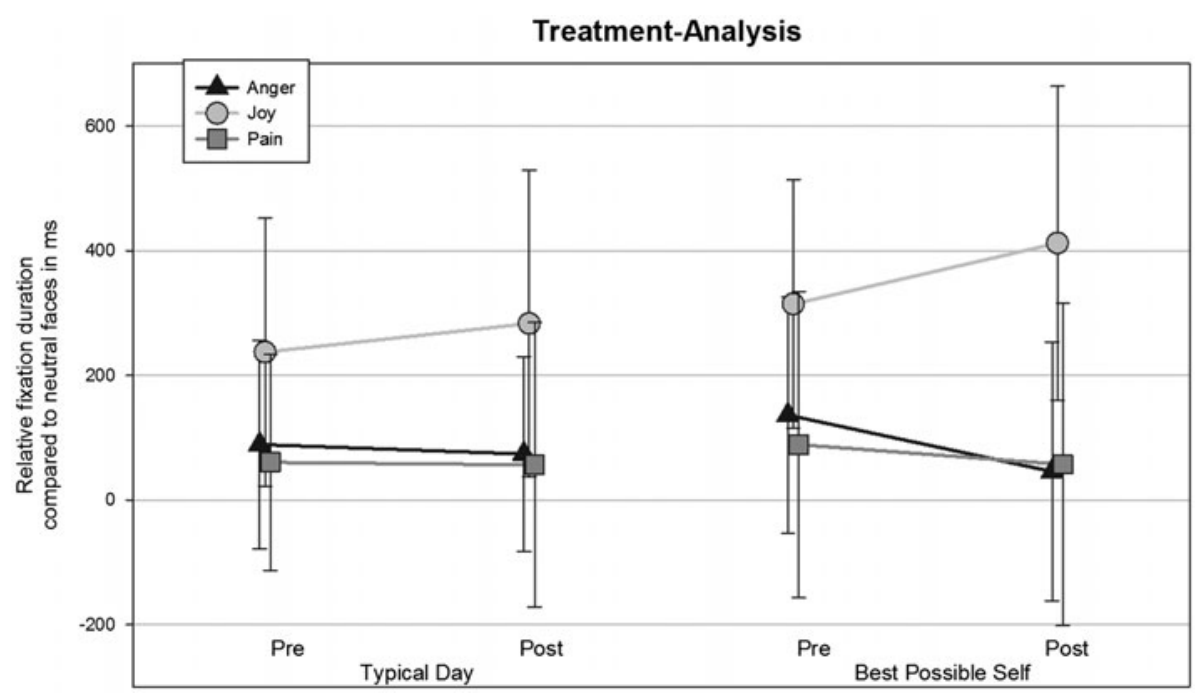

Figure 1. Mean $\pm \mathrm{SD}$ of the fixation bias (relative fixation duration for the emotional/pain faces compared to the neutral faces presented in the same trials) determined pre and post the induction of optimism (BPS group) compared to the control condition (TD group); positive values are suggestive of longer gaze durations for the emotional/pain faces.

BPS and TD. A 2 (condition) $\times 2$ (time) $\times 3$ (expression) repeated measures ANOVA indicated a significant main effect of expression and a significant interaction effect time $\times$ expression (Table 3 ). Optimism induction did not change gazing behavior: None of the effects including the condition factor reached significance. The expression and time $\times$ expression effects are explained by the fact that across conditions, participants had a stronger fixation bias for joy faces compared to anger and pain faces, and this difference became even more distinct at the second confrontation. Univariate comparisons showed that the fixation bias across the two assessments was significantly longer for joy faces $(312 \mathrm{~ms} \pm 210)$ than for anger faces $(86.3 \mathrm{~ms} \pm 135 ; \quad T=-6.51 ; p<.001)$ and pain faces (65.7 $\mathrm{ms} \pm 178 ; T=-6.92 ; p<.001)$ whereas the latter two expressions did not differ in gaze duration $(T=1.26 ; p=.214)$. The accentuation of the differences between the fixation bias for the three expressions during the second presentation was mainly due to a significant increase in the duration of gazing at joy faces from the first to the second presentation $(\Delta=72 \mathrm{~ms} ; T=-2.64$; $p=.011)$. There was no similar change for anger faces $(\Delta=-53 \mathrm{~ms} ; \quad T=1.65 ; \quad p=.105)$ or pain faces $(\Delta=-18 \mathrm{~ms} ; T=.48 ; p=.637)$.

When the analysis was repeated with dispositional optimism as a covariate, additionally a significant interaction effect for time $\times$ expression $\times$ dispositional optimism was obtained. As reported above, high-optimistic individuals already showed a tendency to gaze more at joy faces during the first presentation, but this became more prominent during the second presentation (Spearmans' $\rho=.442, \quad p=.001$ for the relationship between fixation bias for joy faces and LOT-R scores at the second presentation). The increase in gazing duration for joy faces from the first to the second presentation was also significantly associated with dispositional optimism $(r=.286, p=.03$ for the relationship between $\Delta$ fixation bias for joy faces and LOT-R scores). 
M.L. Peters et al.

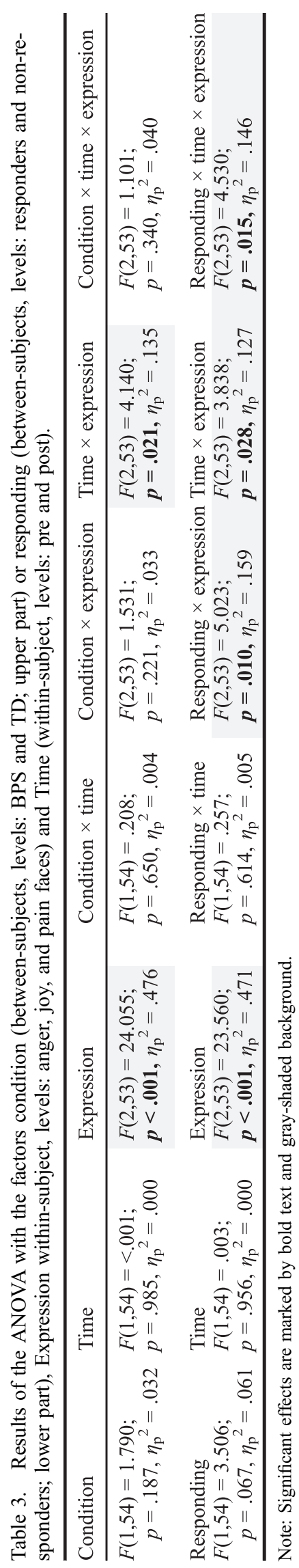




\section{Interaction with dispositional optimism}

The same analyses were carried out with the additional factor 'dispositional optimism' with two levels, which were created by median split of the LOT-R. Participants scoring below 20 on the LOT-R were classified as low optimistic $(n=26)$ and participants scoring 20 or higher were classified as high optimistic $(n=30)$. None of the interactions including the factor dispositional optimism were significant. Thus, the BPS manipulation (optimism induction) did not change fixation bias more in low optimistic participants. Analyses of FEX-pos, FEX-neg, PA, and NA scores neither showed dispositional optimism $\times$ condition $\times$ time interactions. Thus, the BPS manipulation appeared similarly effective in low- and high-optimistic participants.

\section{Post hoc analyses: comparing responders versus non- responders}

Although overall the optimism induction successfully increased positive expectancies for the future and decreased negative expectancies, there were still participants who did not show the expected response pattern in these parameters following the BPS manipulation. By contrast, some participants responded to the TD manipulation. Therefore, we repeated the analyses with a new between-subject factor 'responder'. Responder and nonresponder groups were created on the basis of the change scores on the FEX. First, a total FEX score was created by summing the scores of the FEX-pos items with the reversed scores of the FEX-neg items. Next, a FEX difference score was calculated by subtracting the premanipulation FEX score from the post-manipulation FEX score. The median FEX difference score was 4, and responders were defined as participants having a difference score greater than or equal to the median. Thirty participants were classified as responders $(75 \%$ of the participants of the BPS group), and 26 participants were non-responders ( $68 \%$ of those of the TD group). The distributions of sex and age were similar in the responder (female: 63\%; age: $23.8 \pm 3.8$ years) and non-responder groups (female: $53 \%$; age: $23.1+2.5$ years). In contrast to the original classification according to the optimism induction condition, the two responder groups did not significantly differ in their baseline scores of fear of pain, pain vigilance, and dispositional optimism (see Table 1).

A 2 (responder) $\times 2$ (time) $\times 3$ (expression) repeated measures ANOVA indicated, in addition to the significant expression and time $\times$ expression effects that were already found previously, significant expression $\times$ responder and expression $\times$ time $\times$ responder effects (Table 3 ). Post hoc ANOVA were performed within each group separately to clarify these effects. Within the nonresponder group, only the main effect of expression reached significance $(F(2,24)=8.38 ; \quad p=.002$, $\left.\eta_{\mathrm{p}}{ }^{2}=.411\right)$ but there was no expression $\times$ time interaction $\left(F(2,24)=2.70 ; p=.088, \eta_{\mathrm{p}}{ }^{2}=.183\right)$. In the responder group, both a main effect of expression $(F(2,28)$ $\left.=19.34 ; p<.001, \eta_{\mathrm{p}}{ }^{2}=.589\right)$ and an expression $\times$ time interaction $\left(F(2,28)=5.84 ; p=.008, \eta_{\mathrm{p}}{ }^{2}=.294\right)$ were found. This means that only in the group of responders fixation bias changed from the first to the second presentation dependent on the emotional category. Responders gazed significantly less at anger faces $(T=2.70$; $p=.012, d=.994)$ and nearly significantly more at joy faces $(T=-1.99 ; p=.056, d=.738)$ from pre- to postmanipulation (see Figure 2). The changes in gazing behavior did not reach significance in the non-responder group.

\section{Discussion}

This study was set up to examine whether dispositional optimism as well as induced optimism would be associated with attention toward positive visual stimuli and away from negative visual stimuli (i.e. faces displaying positive and negative emotions). Our hypotheses were partly confirmed. Dispositional optimism showed a trend toward a significant association with fixation bias for joy faces at the first presentation (which became significant after deleting one outlying data point) and a significant correlation with fixation bias for joy faces at the second presentation. There was an overall increase in looking at joy faces from the first to second presentation, but more optimistic participants showed a stronger increase.

The induction of an optimistic state at first did not appear to lead to enhanced gazing at joy faces or diminished gazing at angry faces. However, post hoc analyses indicated that participants who actually responded to the manipulation as intended by an increase in state optimism (i.e. more positive and less negative expectancies for the future) did change their gazing behavior after the manipulation. These participants seemed to improve their 'look on the bright side of life' by gazing significantly less at anger faces and nearly significantly more at joy faces when being confronted with these pictures for a second time. It should be noted that although most responders were found in the optimism induction group $(n=21 ; 70 \%)$, some participants $(n=9 ; 30 \%)$ increased their state optimism after the TD manipulation. The finding that 'responder' analysis after the BPS manipulation is more sensitive than the analysis with the original experimental groups is in accordance with another recent study, in which it was found that overall the BPS and TD group did not significantly differ in conditioned fear responses, but that a different pattern of responding was found when the magnitude of the change after the manipulation was used instead (Geschwind et al., 2015). 


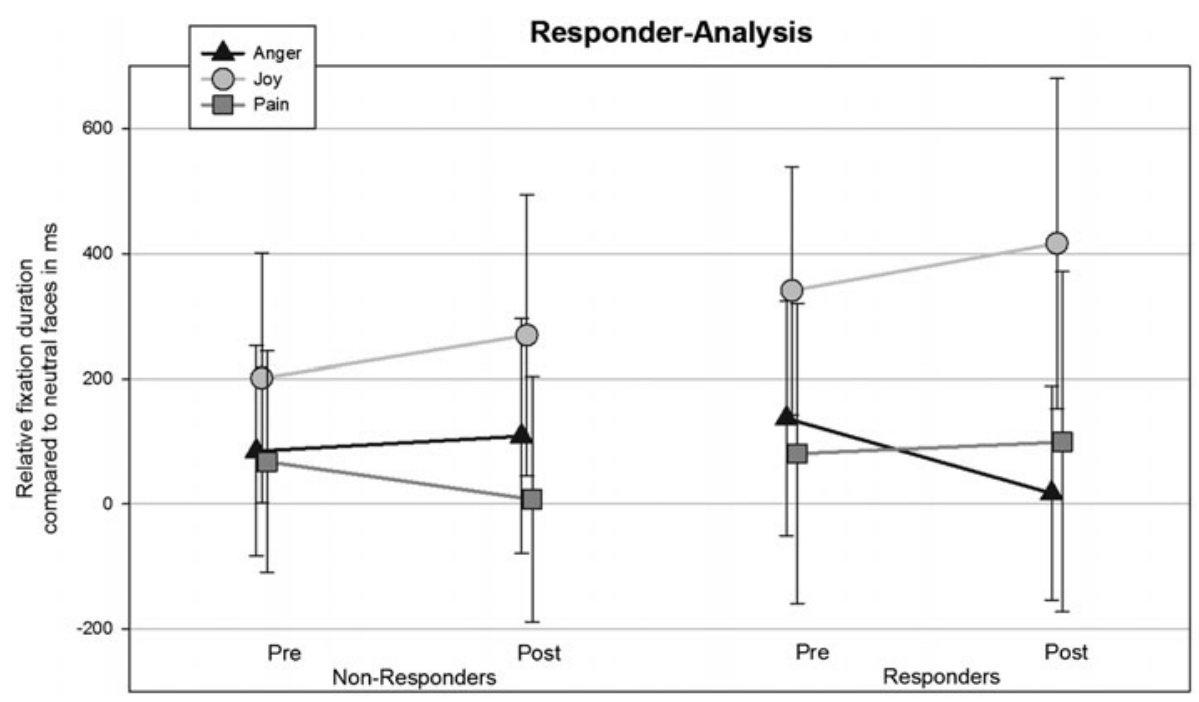

Figure 2. Mean $\pm \mathrm{SD}$ of fixation bias (relative fixation duration for the emotional/pain faces compared to the neutral faces presented in the same trials) determined pre- and post-manipulation in responders (more positive future expectancies and less negative future expectancies) and non-responders; positive values are suggestive of longer gaze durations for the emotional/pain faces.

Previous eye-tracking studies have shown that people in general have a preference to attend to positive images compared to negative or neutral ones (e.g. Sanchez, Vazquez, Gomez, \& Joormann, 2014), a results that is replicated in this study. A general positive attentional bias is consistent with the notion that optimistic biases are common in the general population, i.e. most people tend to look on the bright side of life. Focusing on positive information, while ignoring negative information, might maintain this optimistic outlook (Sharot et al., 2011). Despite a general preference for positive information, there are individual differences in attention deployment. Most research has focused on the association between attentional biases and individual differences in fear and anxiety. Anxious individuals are more likely to show a preference to attend to threatening information in their environment, which in turn might maintain their anxiety (Van Bockstaele et al., 2014; Yiend, 2010). Although most of these studies have used reaction-time paradigms, recent studies using the eye-tracking methodology to assess attention toward emotional faces, have similarly found that individual differences in anxiety are related to attentional preference for faces displaying negative emotions (Shechner, Jarcho, \& Britton, 2013). Attentional deployment toward positive faces has less often been studied, but the available evidence suggests reduced gazing at positive stimuli is more typical for dysphoria than for anxiety (Armstrong \& Olatunji, 2012), although the usually found bias for positive faces may also be absent in individuals with social anxiety (Chen, Clarke, MacLeod, \& Guastella, 2012; Schofield, Inhoff, \& Coles, 2013).
This study focused on individual differences in the level of optimism and found it to be related to a more prominent bias toward gazing at positive faces and less time spent at the anger faces. This is consistent with the findings of earlier studies, using different methodologies and stimulus material, which also demonstrated that optimists preferentially focus on positive cues and turn away from negative ones (Isaacowitz, 2005; Karademas et al., 2007; Segerstrom, 2001). However, this is the first study to examine whether inducing a transient optimistic state changes emotional gazing. In fact, induced state optimism enhanced (the already prominent) attentional bias for positive faces and decreased gazing at negative faces. This suggests that positive interventions can affect the early stages of information processing and lead to the preferential selection of positive stimuli and avoidance of negative stimuli. Previous studies demonstrated that positive imagery could lead to positive interpretation and memory biases (Holmes et al., 2009; Pictet et al., 2011; Torkan et al., 2014; Tran et al., 2011) and this study demonstrated that this might be extended to positive attentional biases.

Previously, positive mood induction was found to increase selective attention toward positive stimuli (Tamir \& Robinson, 2007) and it cannot be excluded that the present findings are attributable to the increase in positive mood. However, such an interpretation is elusive because effects on future expectancies were maintained during the entire experimental session, whereas mood effects appeared to be short lived and had vanished after the eye-tracking task. It may also be noted that previous findings with dispositional optimism were 
all maintained after controlling for current mood (Isaacowitz, 2005; Karademas et al., 2007; Segerstrom, 2001). Nevertheless, optimism and positive mood are intrinsically related and it may theoretically not be feasible to keep these constructs strictly separate.

A positive attentional bias may be functional in that it can protect individuals against the development of negative thoughts and feelings (Matthews \& Antes, 1992). Absence of attention to positive stimuli could lead to depression and distorted assumptions and beliefs about the world (Armstrong \& Olatunji, 2012). In contrast, paying frequent and prolonged attention toward positive stimuli may initiate repeated activation of positive cognitive schemas and concomitant thoughts, emotions and behaviors (Karademas et al., 2007). Segerstrom (2001) has further speculated that attending to the positive aspects of a situation increases the chance that these aspects will be incorporated into the understanding of that situation, and thus may stimulate positive (re)interpretations. Lastly, attending to positive stimuli may contribute to obtaining reward and facilitating success experiences. Noticing rewarding stimuli in one's environment increases the likelihood of actually obtaining them (Tamir \& Robinson, 2007). Nevertheless, even when a positive focus is generally considered adaptive, extreme forms of positive biases and concomitant neglect of threat signals may become dysfunctional. In this study, angry faces were ignored. This may not be problematic in the safe surroundings of a laboratory and when using static pictures, but in real life, neglect of angry expressions of an opponent might be dangerous. Therefore, an emotionally balanced attentional allocation, with attention to positive features when possible, and attention to negative features when necessary, may be considered most adaptive.

Future studies should find out whether positive attentional training could be employed to increase optimism and other positive states and traits. Attentional bias modification away from negative material has been found effective for improving symptoms in anxiety disorders in numerous studies, but positive attentional bias training has much less frequently been employed. One study showed that training people to attend to positive images led to subsequent avoidance of highly negative images, which was interpreted as improved emotion regulation (Wadlinger \& Isaacowitz, 2008). Dandeneau, Baldwin, Baccus, Sakellaropoulo, and Pruessner (2007), trained participants to find a positive emotional face intermixed within negative emotional faces and found that this led to less subjective and physiological stress reactivity and to increased self-confidence. Finally, Johnson (2009) trained participants to look away from angry faces and toward smiling ones. Compared to control participants, these participants showed less frustration in a subsequent stress task. Whether positive attention training can have more pervasive positive effects and instigate the upwards spiral as suggested by the broaden-and-build theory remains to be determined. Nevertheless, one could propose that the BPS writing and imagery technique is itself a type of positive attention training: It stimulates attentional focus on the positive aspects of an imagined future. The BPS has already been shown to have positive consequences on optimism and mood, especially when employed over longer periods of time (Boehm, Lyubomirsky, \& Sheldon, 2011; Lyubomirsky, Dickerhoof, Boehm, \& Sheldon, 2011; Meevissen, Peters, \& Alberts, 2011; Peters, Meevissen, \& Hanssen, 2013; Shapira \& Mongrain, 2010; Sheldon \& Lyubomirsky, 2006).

On a more general level, this study is also relevant for gaining further insight in the effectiveness of a single-session BPS exercise. We have previously demonstrated that a single 20-minute writing and visualization exercise is able to positively change expectancies for the future, along with an increase in positive affect. So far, we have only looked at the effects immediately after completion of the exercise, this study looked for the first time at relatively sustained effects, i.e. the maintenance of positive expectancies and affect after performing an unrelated task for approximately $20 \mathrm{~min}$ (i.e. eye tracking). Interestingly, the mood effects appeared to be shorted-lived, whereas the effects on expectancies remained significant over the entire experimental session, declining only marginally. Previously, we also demonstrated that a longer version of this intervention with daily visualization for one or two weeks elevated dispositional optimism (Meevissen et al., 2011; Peters, Meevissen, \& Hanssen, 2013), an effect that was maintained at least until one week after the completion of the intervention, whereas its effect on life satisfaction was not maintained at follow-up (Peters et al., 2013). This suggests also that the BPS exercise can be regarded as an optimism induction more than as a mood induction.

Exploratory, we examined the correlates of gazing at pain faces. Previously, we found that the BPS manipulation led to lower pain sensitivity and less cognitive interference by pain in healthy volunteers (Boselie et al., 2014; Hanssen et al., in press). One of the underlying mechanisms may be a lesser focus on pain after the optimism induction. A previous study using the dot-probe paradigm found that increased attention toward pain faces was related to increased pain sensitivity in healthy volunteers (Baum, Huber, \& Schneider, 2011). However, in this study, there was no association with dispositional or induced optimism and gaze duration for the pain faces. Moreover, neither pain vigilance nor fear of pain assessed at baseline correlated with gazing at pain faces.

A limitation of this study was that we only included young healthy students who are characterized by a relatively high level of dispositional optimism. This may 
undermine the power to detect individual differences due to range restrictions. Furthermore, the advantage of eye tracking by assessing the attractiveness of emotional contents in direct competition was not fully utilized because within a given trial always one emotional face was presented concurrently with a neutral face. The presentation of several emotional categories at a screen in parallel would allow for determining the so-called scan path. The scan path reveals how individuals shift their focus of attention with epochs of engagement and disengagement and might be different for optimistic and non-optimistic persons when exploring emotional material. The restricted format of presentation was nevertheless chosen to compare the findings better with the still more prevalent dot-probe task findings.

To conclude, this study shows that attentional deployment may be one of the mechanisms underlying and maintaining a positive outlook on life. Future studies could further explore the automaticity of these attentional processes and their relation to more positive interpretation and memory biases.

\section{Disclosure statement}

No potential conflict of interest was reported by the authors.

\section{References}

Armor, D. A., \& Taylor, S. E. (1998). Situated optimism: Specific outcome expectancies and self-regulation. In M. P. Zanna (Ed.), Advances in Experimental Social Psychology (Vol. 30, pp. 309-379). New York, NY: Academic Press.

Armstrong, T., \& Olatunji, B. O. (2012). Eye tracking of attention in the affective disorders: A meta-analytic review and synthesis. Clinical Psychology Review, 32, 704-723. doi:10.1016/j.cpr.2012.09.004

Baum, C., Huber, C., \& Schneider, R. (2011). Prediction of experimental pain sensitivity by attention to pain-related stimuli in healthy individuals. Perceptual and Motor Skills, 112, 926-946. doi:10.2466/02.09.22.PMS.112.3.926-946

Baum, C., Kappesser, J., Schneider, R., \& Lautenbacher, S. (2013). Does vigilance to pain make individuals experts in facial recognition of pain? Pain Research and Management, 18, 191-196. Retrieved from http://www.pul sus.com/journals/journalHome.jsp?sCurrPg=journal\&jnlKy= 7\&/home2.htm

Baum, C., Schneider, R., Keogh, E., \& Lautenbacher, S. (2013). Different stages in attentional processing of facial expressions of pain: A dot-probe task modification. The Journal of Pain, 14, 223-232. doi:10.1016/ j.jpain.2012.11.001

Blackwell, S. E., Rius-Ottenheim, N., Schulte-van Maaren, Y. W. M., Carlier, I. V. E., Middelkoop, V. D., Zitman, F. G., ... Giltay, E. J. (2013). Optimism and mental imagery: A possible cognitive marker to promote well-being? Psychiatry Research, 206, 56-61. doi:10.1016/j.psychres. 2012.09.047

Boehm, J. K., Lyubomirsky, S., \& Sheldon, K. M. (2011). A longitudinal experimental study comparing the effectiveness of happiness-enhancing strategies in Anglo Americans and
Asian Americans. Cognition \& Emotion, 25, 1263-1272. doi:10.1080/02699931.2010.541227

Boselie, J. J. L. M., Vancleef, L. M. G., Smeets, T., \& Peters, M. L. (2014). Increasing optimism abolishes pain-induced impairments in executive task performance. Pain, 155, 334-340. doi:10.1016/j.pain.2013.10.014

Carver, C. S. (2001). Affect and the functional bases of behavior: On the dimensional structure of affective experience. Personality and Social Psychology Review, 5, 345-356. doi:10.1207/S15327957PSPR0504_4

Chen, N. T. M., Clarke, P. J. F., MacLeod, C., \& Guastella, A. J. (2012). Biased attentional processing of positive stimuli in social anxiety disorder: An eye movement study. Cognitive Behaviour Therapy, 41, 96-107. doi:10.1080/ 16506073.2012.666562

Dandeneau, S. D., Baldwin, M. W., Baccus, J. R., Sakellaropoulo, M., \& Pruessner, J. C. (2007). Cutting stress off at the pass: Reducing vigilance and responsiveness to social threat by manipulating attention. Journal of Personality and Social Psychology, 93, 651-666. doi:10.1037/0022-3514.93.4.651

Garland, E. L., Fredrickson, B., Kring, A. M., Johnson, D. P., Meyer, P. S., \& Penn, D. L. (2010). Upward spirals of positive emotions counter downward spirals of negativity: Insights from the broaden-and-build theory and affective neuroscience on the treatment of emotion dysfunctions and deficits in psychopathology. Clinical Psychology Review, 30, 849-864. doi:10.1016/j.cpr.2010.03.002

Geschwind, N., Meulders, M., Peters, M. L., Vlaeyen, J. W. S., \& Meulders, A. (2015). Can experimentally induced positive affect attenuate generalization of fear of movement-related pain? Journal of Pain, 16, 258-269. doi:10.1016/j.jpain.2014.12.003

Glaesmer, H., Hoyer, J., Klotsche, Herzberg, \& P. Y. (2008). Die deutsche Version des Life-Orientation-Tests (LOT-R) zum dispositionellen Optimismus und Pessimismus. Zeitschrift für Gesundheitspsychologie, 16, 26-31. Retrieved from http://www.hogrefe.de/zeitschriften/zeitschrift-fuer-ge sundheitspsychologie/

Glaesmer, H., Rief, W., Martin, A., Mewes, R., Brähler, E., Zenger, M., \& Hinz, A. (2012). Psychometric properties and population-based norms of the Life Orientation Test Revised (LOT-R). British Journal of Health Psychology, 17, 432-445. doi:10.1111/j.2044-8287.2011.02046.x

Hanssen, M. M., Peters, M. L., Vlaeyen, J. W., Meevissen, Y. M., \& Vancleef, L. M. (2013). Optimism lowers pain: Evidence of the causal status and underlying mechanisms. Pain, 154, 53-58. doi:10.1016/j.pain.2012.08.006

Hanssen, M. M., Vancleef, L. M., \& Peters, M. L. (in press). What does it mean to be an optimist in an ambiguous world? Investigating negative versus positive interpretation patterns of optimists. Manuscript submitted for publication.

Holmes, E. A., Lang, T. J., \& Shah, D. M. (2009). Developing interpretation bias modification as a 'cognitive vaccine' for depressed mood: Imagining positive events makes you feel better than thinking about them verbally. Journal of Abnormal Psychology, 118, 76-88. doi:10.1037/ a0012590

Isaacowitz, D. M. (2005). The gaze of the optimist. Personality and Social Psychology Bulletin, 31, 407-415. doi:10.1177/ 0146167204271599

Johnson, D. R. (2009). Goal-directed attentional deployment to emotional faces and individual differences in emotional regulation. Journal of Research in Personality, 43, 8-13. doi:10.1016/j.jrp.2008.09.006 
Karademas, E. C., Kafetsios, K., \& Sideridis, G. D. (2007). Optimism, self-efficacy and information processing of threat and well-being-related stimuli. Stress and Health, 23, 285-294. doi:10.1002/smi.1147

King, L. A. (2001). The health benefits of writing about life goals. Personality and Social Psychology Bulletin, 27, 798-807. doi:10.1177/0146167201277003

Krohne, H. W., Egloff, B., Kohlmann, C.-W., \& Tausch, A. (1996). Investigations with a German version of the Positive and Negative Affect Schedule (PANAS). Diagnostica, 42, 139-156. Retreived from http://www.hogrefe.de/zeits chriften/diagnostica/

Lyubomirsky, S., Dickerhoof, R., Boehm, J. K., \& Sheldon, K. M. (2011). Becoming happier takes both a will and a proper way: An experimental longitudinal intervention to boost well-being. Emotion, 11, 391-402. doi:10.1037/ a0022575

Matthews, G. R., \& Antes, J. R. (1992). Visual attention and depression: Cognitive biases in the eye fixations of the dysphoric and the nondepressed. Cognitive Therapy and Research, 16, 359-371.

McCracken, L. M. (1997). "Attention" to pain in persons with chronic pain: A behavioral approach. Behavior Therapy, 28, 271-284. doi:10.1037/0021-843X.116.1.80

McNeil, D. W., \& Rainwater, A. J. (1998). Development of the fear of pain questionnaire-III. Journal of Behavioral Medicine, 21, 389-410. doi:10.1016/S0005-7967(00)00049-8

Meevissen, Y. M. C., Peters, M. L., \& Alberts, H. J. E. M. (2011). Become more optimistic by imagining a best possible self: Effects of a two week intervention. Journal of Behavior Therapy and Experimental Psychiatry, 42, 371378. doi:10.1016/j.jbtep.2011.02.012

Peters, M. L., Flink, I. K., Boersma, K., \& Linton, S. J. (2010). Manipulating optimism: Can imagining a best possible self be used to increase positive future expectancies? The Journal of Positive Psychology, 5, 204-211. doi:10.1080/17439761003790963

Peters, M. L., Meevissen, Y. M. C., \& Hanssen, M. M. (2013). Specificity of the Best Possible Self intervention for increasing optimism: Comparison with a gratitude intervention. Terapiapsicológica, 31, 93-100. Retreived from http:// teps.cl/

Pictet, A., Coughtrey, A. E., Mathews, A., \& Holmes, E. A. (2011). Fishing for happiness: The effects of generating positive imagery on mood and behaviour. Behaviour Research and Therapy, 49, 885-891. doi:10.1016/ j.brat.2011.10.003

Renner, F., Schwarz, P., Peters, M. L., \& Huibers, M. (2014). Effects of a best-possible-self mental imagery exercise on mood and dysfunctional attitudes. Psychiatry Research, 215, 105-110. doi:10.1016/j.psychres.2013.10.033

Sanchez, A., Vazquez, C., Gomez, D., \& Joormann, J. (2014). Gaze-fixation to happy faces predicts mood repair after a negative mood induction. Emotion, 14, 85-94. doi:10.1037/ a 0034500

Scheier, M. F., Carver, C. S., \& Bridges, M. W. (1994). Distinguishing optimism from neuroticism (and trait anxiety, selfmastery, and self-esteem): A reevaluation of the Life Orientation Test. Journal of Personality and Social Psychology, 67, 1063-1078. doi:10.1037/0022-3514.67.6.1063

Schofield, C. A., Inhoff, A. W., \& Coles, M. E. (2013). Timecourse of attention biases in social phobia. Journal of Anxiety Disorders, 27, 661- 669. doi:10.1016/j.janxdis.2013. 07.006
Segerstrom, S. C. (2001). Optimism and attentional bias for negative and positive stimuli. Personality and Social Psychology Bulletin, 27, 1334-1343. doi:10.1177/ 01461672012710009

Shapira, L. B., \& Mongrain, M. (2010). The benefits of selfcompassion and optimism exercises for individuals vulnerable to depression. The Journal of Positive Psychology, 5, 377-389. doi:10.1037/a0035536

Sharot, T., Korn, C. W., \& Dolan, R. J. (2011). How unrealistic optimism is maintained in the face of reality. Nature Neuroscience, 14, 1475-1479. doi:10.1038/nn.2949

Shechner, T., Jarcho, J. M., \& Britton, J. C. (2013). Attention bias of anxious youth during extended exposure of emotional face pairs: An eye-tracking study. Depression and Anxiety, 30, 14-21. doi:10.1002/da.21986

Sheldon, K. M., \& Lyubomirsky, S. (2006). How to increase and sustain positive emotion: The effects of expressing gratitude and visualizing best possible selves. The Journal of Positive Psychology, 1, 73-82. doi:10.1080/ 17439760500510676

Simon, D., Craig, K. D., Gosselin, F., Belin, P., \& Rainville, P. (2008). Recognition and discrimination of prototypical dynamic expressions of pain and emotions. Pain, 135, 5564. doi:10.1016/j.pain.2007.05.008

Tamir, M., \& Robinson, M. D. (2007). The happy spotlight: Positive mood and selective attention to rewarding information. Personality and Social Psychology Bulletin, 33, 1124 1136. doi:10.1177/0146167207301030

Torkan, H., Blackwell, S. E., Holmes, E. A., Kalantari, M., Neshat-Doost, H. T., Maroufi, M., \& Talebi, H. (2014). Positive imagery cognitive bias modification in treatmentseeking patients with major depression in Iran: A pilot study. Cognitive Therapy and Research, 38, 132-145. doi:10.1007/s10608-014-9598-8

Tran, T., Hertel, P. T., \& Joormann, J. (2011). Cognitive bias modification: Induced interpretive biases affect memory. Emotion, 11, 145-152. doi:10.1037/a0021754

Van Bockstaele, B., Verschuere, B., Tibboel, H., De Houwer, J., Crombez, G., \& Koster, E. W. H. (2014). A review of current evidence for the causal impact of attentional bias on fear and anxiety. Psychological Bulletin, 140, 682-721. doi:10.1037/a0034834

Vancleef, L. M., \& Peters, M. L. (2008). Examining content specificity of negative interpretation biases with the Body Sensations Interpretation Questionnaire (BSIQ). Journal of Anxiety Disorders, 22, 401-415. doi:10.1016/j.janxdis. 2007.05.006

Wadlinger, H. A., \& Isaacowitz, D. A. (2006). Positive mood broadens visual attention to positive stimuli. Motivation and Emotion, 30, 87-99. doi:10.1007/s11031-006-9021-1

Wadlinger, H. A., \& Isaacowitz, D. M. (2008). Looking happy: The experimental manipulation of a positive visual attention bias. Emotion, 8, 121-126. doi:10.1037/1528-3542.8.1.121

Watson, D., Clark, L. A., \& Tellegen, A. (1988). Development and validation of brief measures of positive and negative affect: The PANAS scales. Journal of Personality and Social Psychology, 54, 1063-1070. doi:10.1037/00223514.54.6.1063

Weinstein, N. D. (1980). Unrealistic optimism about future life events. Journal of Personality and Social Psychology, 39, 806-820. doi:10.1037/0022-3514.39.5.806

Yiend, J. (2010). The effects of emotion on attention: A review of attentional processing of emotional information. Cognition \& Emotion, 24, 3-47. doi:10.1080/02699930903205698 